IJBPAS, December, Special Issue, 2021, 10(12): 213-224

ISSN: 2277-4998

International Journal of Biology, Pharmacy

and Allied Sciences (IJBPAS)

'A Bridge Betueen Caboratory and QRendor'

Www.iibpas,com

\title{
RESILIENCE AND WORRY AMONG UNDERGRADUATE MEDICAL STUDENTS: A CROSS-SECTIONAL STUDY
}

\section{IRFAN ANJUM1, ABDULLAH ALHASOON², ABDULMAJEED ASIRI ${ }^{2}$, ABDULLAH ALSALEAM ${ }^{2}$, KHALID ALMALKI ${ }^{2}$, SAJIDA AGHA ${ }^{3}$ AND EMAD MASUADI ${ }^{4}$}

1: Clinical Psychologist, Lancashire and South Cumbria NHS Foundation Trust, Preston, UK

2: Undergraduate Medical Student, College of Medicine, King Saud bin Abdulaziz University for Health Sciences, Riyadh, Saudi Arabia

3: Associate Professor, College of Medicine, King Saud bin Abdulaziz University for Health Sciences, Riyadh, Saudi Arabia

4: Assistant Professor, College of Medicine, King Saud bin Abdulaziz University for Health

Sciences, Riyadh, Saudi Arabia

*Corresponding Author: Dr. Irfan Anjum

Received $19^{\text {th }}$ Aug. 2021; Revised 20 ${ }^{\text {th }}$ Sept. 2021; Accepted $29^{\text {th }}$ Oct. 2021; Available online $1^{\text {st }}$ Dec. 2021 https://doi.org/10.31032/IJBPAS/2021/10.12.2022

\section{ABSTRACT}

Aim and objectives: This research aims to assess resilience and worry among medical students. The objectives are to estimate the prevalence of resilience and worry and to assess the association between resilience and worry among medical students.

Methods: A cross-sectional survey is conducted among medical students in the largest public sector university in Riyadh, Saudi Arabia. The sample is made up of 325 students of both sexes in their first to final years of schooling. The study was conducted during 2018-2019. Demographic information was collected using tools such as the Connor-Davidson Resilience Scale (CD-RISC25) and the Penn State Worry Questionnaire (PSWQ). The Spearman Correlation and ANOVA are used to assess the association between resilience and worry scores. A p-value less than 0.05 is considered 
significant.

Results: The results show that the students' mean total resilience scores are at the average level $(65.8 \pm 13.7)$, and the worry scores are at the low level $(45.5 \pm 9.0)$. Additionally, the study results show a significant negative correlation between resilience and worry $(\mathrm{r}=-.269,<0.001)$.

Conclusion: The study reveals the prevalence of resilience and low worry among medical students. This study shows that average levels of resilience are associated with lower worry. Academic institutions need to promote resilience to improve the mental health of medical students.

Keywords: resilience, worry, medical student, saudi arabia

\section{INTRODUCTION}

Medical students face many pressures throughout their school programs. Studies have reported high rates of depression, anxiety, and stress among medical students in Saudi Arabia [1, 2]. They have identified many causes of depression and anxiety: substantial expectations from society, an overwhelming medical curriculum, a competitive learning environment, and fear of failing later in their professional careers. Psychological resilience is found to have significant psychosocial factors among students. A study reported that resilience is a key factor in helping individuals more efficiently deal with pressure [3].

The American Psychological Association (APA) has defined resilience as "the process of adapting well in the face of adversity, trauma, tragedy, threats, or significant sources of stress" [4]. Resilience can be defined as adapting well in times of misfortune, stress, or trauma and promoting positive changes in the midst of considerable threat [5]. A study defined resilience as an ability to protect individual mental well-being in the face of difficulties and adverse situations that are a result of interactions between the factors of both internal and environmental stress [6, 7, 8]. Although there is no agreed upon definition of resilience, two main components are considered imperative in resilient behavior. The first is behavioral characteristics, such as maintaining high career effectiveness or a healthy social circle, even in difficult situations. The second is psychological characteristics, 
which mainly include the ability to maintain good mental health.

The APA has defined worry as "a state of mental distress or agitation due to concern about an impending or anticipated event, threat, or danger" [10].

One of the most important aspects of the life of a medical student is their mental health, as its stability plays a key role in their academic endeavors. A study in the U.S. and Canada found that resilient students were less likely to be depressed and had better quality of life [11]. Medical students who were less resilient were considered more vulnerable to burn out, depression, and even suicidal ideation [11]. Another study showed that $11 \%$ of medical students who had ideations of dropping out of their programs, or were burnt out, were less resilient [12].

Therefore, the literature has suggested that higher levels of resilience may prevent psychological distress. Many factors are reported to increase the likelihood of resilient behavior and to reduce worry. Psychological problems, which are significantly increased by childhood misfortunes, such as depression, suicidal attempts, drug abuse, or poor general health, may increase the resilience of the children who experience them because they learn to psychologically cope with these issue [9]. Other reported factors that tend to increase resilience are divided into internal and external factors [9]. Internal factors, such as psychological well-being, optimism, and self-efficacy, are generally not very accurate since they can only be measured qualitatively, but they are the most important internal factors that increase resilience. Although external factors are not well established, childhood misfortunes, socioeconomic status, and cultural differences may play a significant role in improving resilience. To address measuring internal factors of resilience, a metric scale was designed to evaluate the variation of responses [1].

The literature suggests that the psychological states of medical students, their ability to prevent negative mental health, and the role of resilience has not yet been sufficiently explored [11]. In researching this paper, we did not find enough literature on resilience, which is a crucial factor in the lives of students and their journeys with education and mental health.

We designed this study to estimate the prevalence of resilience among medical 
students and to assess a possible association between worry and resilience. This research will help fill the gaps in the literature and provide information to medical educators and practitioners on the role of resilience in decreasing worry among students. This information will guide medical educators and institutions in the development of study-skill courses.

\section{MATERIALS AND METHODS}

This study utilizes a descriptive cross-sectional design. All medical students were recruited through convenience sampling (approximately 1,200) from one of the largest public sector medical colleges in Riyadh, Saudi Arabia. The inclusion criteria consist of students who consent to participate in the study and are enrolled in a medical program. Both male and female students, from the first to final year (pre-clinical and clinical years) of their undergraduate medicine program, were invited to participate in the study. The study was conducted over a six-month period between September 2018 and February 2019. The study was approved by the Institutional Review Board (IRB) of King Abdullah International Medical Research Center.

Raosoft Inc.'s sample size calculator was used to estimate the sample size. A sample of 377 students was required for a confidence level of $95 \%$ and a $5 \%$ margin of error.

The data was collected by the research team using two self-administered scales: the CD-RISC25, which tested resilience level and consisted of 25 items on a fourpoint Likert scale (not true at all (0), rarely true (1), sometimes true (2), often true (3), and true nearly all of the time (4)) $[13,14]$. The answers to this questionnaire categorized the participants as either "resilient" or "non-resilient." The total scores range from 0 to 100 , and higher total scores indicate higher levels of resilience [15]. The other scale, the PSWQ, consisted of 16 items on a fivepoint Likert scale, designed to measure worry with a reliability of 0.89 [16]. Items are rated on a five-point scale from 1 , not at all typical of me, to 5, very typical of me. Possible scores range from 16 to 80 , with total scores of 16 to 39 indicating "low worry," 40 to 59 indicating "moderate worry," and 60 to 80 indicating "high worry" [16].

The authors approached students in their respective classes. They were given printed copies of the questionnaires in English and assured of the confidentiality 
of their data and their rights to withdraw from the study. Utmost care was taken to ensure privacy and confidentiality. The medical students first completed a form about demographic information before responding to the resilience and worry questionnaires.

After data cleaning and assigning codes, SPSS (version 20; IBM, USA) was used for data analysis. Frequency and percentage computed for categorical variables, mean, standard deviations, and Median (Q1-Q3) were used for the continuous variables that were not normally distributed. The Spearman correlation test was used to assess the association between total resilience scores and total worry scores. To measure the association between resilience and worry with the student's demographic profile, an ANOVA test was used. The pvalue of $<0.05$ was considered significant in all the applied tests.

\section{RESULTS}

The present study was conducted to explore resilience among medical students and to find the correlation between resilience and worry. Table 1 shows the demographics of the students. A total 325 medical students with a response rate of $86 \%$ participated in the study. The mean age of the participating students was $22 \pm 2.0$ years. Two hundred and fourteen (66\%) were male students, and $111(32 \%)$ were female students. Among them, 25 (7.7\%) students were in their fourth year, $47(14.5 \%)$ were in their third year, 179 (55\%) were in their second year, and 74 (22.8\%) were in their first year. Table 1 shows the highest participation was from batch 14 (second year), and most of them were males of 21 years of age.

Table 2 shows the level of resilience and worry among medical students. The total mean score of resilience was 65.8 , while the standard deviation was 13.7. However, the total mean score of worry was 45.5, while the standard deviation was 9.0. This means that there were high levels of resilience and low levels of worry among students.

The median score on the Penn State Worry Questionnaire was 45 (39-52). The median score on the ConnorDavidson Resilience Scale was 66 (5775). These results confirm that students with high resilience scored low on the worry questionnaire.

Our study examined the relationship between levels of resilience and worry and found a negative relationship 
between them $(r=-.269, p=0.001)$. The results suggest that high resilience decreases worry among medical students. In other words, the higher someone's resilience, the lower their amount of worry Table 3.

Additionally, the analysis was performed to establish a baseline profile between the medical students' total scores on the PSWQ and their total scores on the CD-
RISC25. A statistically significant connection was observed between worry and gender $(\mathrm{p}<0.04)$. In our study, only a marginal connection was found between resilience and age of the students $(p=0.057)$. However, the results show no significant relationship between worry or resilience with year of study $(p=0.38$, $\mathrm{p}=0.71$, respectively) Table 4 .

Table 1: Sample characteristics $(\mathrm{N}=325)$

\begin{tabular}{|ccc|}
\hline Demographics & $\mathbf{N}$ & Mean \pm SD \\
\hline Age & 325 & $22 \pm 2$ \\
& Batch & $7.7 \%$ \\
12 & 25 & $14.5 \%$ \\
13 & 47 & $55.1 \%$ \\
14 & 179 & $22.8 \%$ \\
Male & 74 & \\
Female & Gender & $65.8 \%$ \\
& 214 & $34.2 \%$ \\
20 & 111 & $16.0 \%$ \\
21 & Age (years) & $43.4 \%$ \\
22 & 52 & $18.5 \%$ \\
23 & 141 & $9.5 \%$ \\
$24+$ & 60 & $12.6 \%$ \\
\hline
\end{tabular}

Table 2: shows the mean scores of resilience and worry of the medical students

\begin{tabular}{|cccccc|}
\hline Scales & N & Mean+SD & Median & Q1 & Q3 \\
\hline the total score for the Penn State & & & & & \\
Worry Questionnaire & $\mathbf{3 2 5}$ & $\mathbf{4 5 . 5 \pm 9 . 0}$ & $\mathbf{4 5}$ & $\mathbf{3 9}$ & $\mathbf{5 2}$ \\
$\begin{array}{c}\text { the total score for the Connor-Davidson } \\
\text { Resilience Scale }\end{array}$ & $\mathbf{3 2 5}$ & $\mathbf{6 5 . 8 \pm 1 3 . 7}$ & $\mathbf{6 6}$ & $\mathbf{5 7}$ & $\mathbf{7 5}$ \\
\hline
\end{tabular}

Table 3: the correlation between the Penn State Worry and Conner Davidson Resilience scores

\begin{tabular}{|ccc|}
\hline Correlations & $\begin{array}{c}\text { the total score for the Penn } \\
\text { State Worry Questionnaire }\end{array}$ & $\begin{array}{c}\text { the total score for the Connor- } \\
\text { Davidson Resilience Scale }\end{array}$ \\
\hline $\begin{array}{c}\text { the total score for the Penn State } \\
\text { Worry Questionnaire }\end{array}$ & 1 & $-.269 * *$ \\
$P$ Value & & $<0.001$ \\
the total score for the Connor- & $-.269 * *$ & 1 \\
Davidson Resilience Scale 25 & & \\
$P$ Value & $<0.001$ & \\
\hline
\end{tabular}


Table 4: Association between demographics and Worry, and Resilience scores

\begin{tabular}{|c|c|c|c|c|}
\hline Group Statistics & Variables & $\mathbf{N}$ & Mean+SD & P-value \\
\hline \multicolumn{5}{|c|}{ Gender } \\
\hline \multirow[b]{2}{*}{ The total The Penn State Worry Score } & Male & 214 & $44.8 \pm 8.5$ & \multirow{2}{*}{0.04} \\
\hline & Female & 111 & $46.9+9.6$ & \\
\hline \multirow[t]{2}{*}{ The total the Connor-Davidson Resilience Score } & Male & 214 & $66.2 \pm 13.3$ & \multirow{2}{*}{0.37} \\
\hline & Female & 111 & $64.8 \pm 14.4$ & \\
\hline \multicolumn{5}{|c|}{ Age } \\
\hline \multirow{6}{*}{ The total The Penn State Worry Score } & 20 & 52 & $46.9 \pm 9.8$ & \multirow{6}{*}{0.43} \\
\hline & 21 & 141 & $44.7+8.8$ & \\
\hline & 22 & 60 & 46.5ㅍ․6 & \\
\hline & 23 & 31 & $46.1+9.2$ & \\
\hline & $24+$ & 41 & $44.3 \pm 8.5$ & \\
\hline & Total & 325 & $45.5 \pm 9.0$ & \\
\hline \multirow{6}{*}{ The total the Connor-Davidson Resilience Score } & 20 & 52 & $65.9 \pm 16.2$ & \multirow{6}{*}{$\mathbf{0 . 0 5 7}$} \\
\hline & 21 & 141 & $64.6 \pm 12.9$ & \\
\hline & 22 & 60 & $67.6+14.4$ & \\
\hline & 23 & 31 & $61.6 \pm 12.4$ & \\
\hline & $24+$ & 41 & $70.1 \pm 11.7$ & \\
\hline & Total & 325 & $65.8+13.7$ & \\
\hline \multicolumn{5}{|c|}{ Batch } \\
\hline \multirow{5}{*}{ The total The Penn State Worry Score } & 12 & 25 & $43.8 \pm 9.3$ & \multirow{5}{*}{$\mathbf{0 . 3 8}$} \\
\hline & 13 & 47 & $46.8+8.2$ & \\
\hline & 14 & 179 & $45.0 \pm 8.8$ & \\
\hline & 15 & 74 & $46.3 \pm 9.8$ & \\
\hline & Total & 325 & $45.5 \pm 9.0$ & \\
\hline \multirow{5}{*}{ The total the Connor-Davidson Resilience Score } & 12 & 25 & $67.9 \pm 12.1$ & \multirow{5}{*}{0.71} \\
\hline & 13 & 47 & $66.3 \pm 13.3$ & \\
\hline & 14 & 179 & $65.9 \pm 13.6$ & \\
\hline & 15 & 74 & $64.4 \pm 14.8$ & \\
\hline & Total & 325 & $65.8 \pm 13.7$ & \\
\hline
\end{tabular}

\section{DISCUSSION}

This study assesses the levels of resilience and worry in medical students. Good mental health is important in keeping people immune to unwanted or overwhelming situations. Traditionally, studies on the well-being of students have focused on susceptibility or risk factors, rather than preventative features. The students' mean score of resilience in this study is at the average level. Our results are comparable to a study that reported an average level resilience score among medical students [17]. However, our results are below the normal level of undergraduate medical students in the U.S., who had higher mean resilience scores (75.7). Consistent with our hypothesis, in this study, medical students with average resilience levels had less worry. Similar findings were reported in previous studies that identified resilience as negatively associated with distress $[17,18]$. These relationships were independent of gender, age, or year of medical school. 
Furthermore, Brailovskaia's study worry compared to their male conducted on Chinese, German, and Russian students concluded that resilient and socially supported students were less vulnerable to and less affected by mental health problems [20]. The literature reveals that resilience is a mediating factor between the incidence of stressful events and personal growth, [11] which may support the shaping of new adaptive behaviors [21].

Gender differences in resilience were not significant in this study, where male students scored 66.2 and females scored 64.8. We measured students' worry levels using the PSWQ and calculated a mean score of 45. Male students scored lower in worry levels: 44.8 compared to 46.9 in females. Similarly, gender difference in terms of resilience was found in one study conducted in Iran, where men had a resilience score of 58.7, and women had a score of 57.4 [22]. Conversely, several studies on medical students revealed that men did better than women on the resilience scale in China, the United States, and Canada [17,23,24]. While analyzing the results of our study on the worry questionnaire, we found that gender had a significant effect. It showed that females have increased levels of

counterparts. This finding is also present in a Rio University study, where significant gender differences indicated that females had higher anxiety levels compared to males [25]. This gender difference is also seen in a study performed with Brazilian medical students, which concluded that the female sex was associated with increased levels of depression and anxiety [26].

Interestingly, in our study, resilience and worry scores were not significantly different among medical students in different years of the medical program. Our results are similar to a study that reported no significant difference between resilience and year of study [27]. The results are surprising, as there are many aspects of medical education that tend to influence resilience of undergraduate medical students. These results address the gaps in the curriculum and educational strategies that are not designed to improve the resilience of medical students.

Additionally, a qualitative study conducted among medical students explored the factors associated with quality of life during medical school. It revealed that curriculum, quality of 
instructors, lifestyle factors, such as sleep, eating habits, and physical activity had great influence on students' wellbeing [28]. Counseling was shown to increase resilience scores and to help develop coping strategies to deal with stressors in a study where college students had an increase of three points in mean resilience in the CD-RISC25 at the University of Texas in the United States [16].

However, there are limitations. First, this is one institutional study and cannot represent all medical university students. Second, small sample size may have an impact on the significance of the results in this cross-sectional study. Third, we were not able to find cutoff scores for the two scales, which limits the ability to extensively analyze the responses. Finally, due to male and female students being on separate campuses, our data on female students was affected by poor response and questionnaire distribution.

Although there are certain limitations, the results have worldwide implications, even on the general population. The results are accurate within the narrow scope of medical students and are similar when compared to other nationalities examining the same subset of the population. Using globally recognized tools to collect data allowed us to confidently compare our findings with many sets of data obtained and published by different research groups around the world and will allow them to be applicable to different settings and populations.

Our study is the first to explore resilience and its association with worry among medical students in Saudi Arabia. Resilience is an important subject that requires further focus in the future. Longitudinal studies with large samples are recommended. Additionally, in order to increase the reliability of the tools and be culturally established, a cutoff score for each scale is recommended. As this is one institution-based study, the use of a multicenter approach in future studies will increase the generalizability of the results and help in the development of well-being programs. Finally, university facilities should implement plans to equip students seeking help with their mental health by providing adequate coping techniques to improve outlook.

\section{CONCLUSION}

In conclusion, the results postulate that resilience has a significant effect on mental well-being. The study revealed a 
prevalence of average resilience and low worry among medical students. This study shows that average levels of resilience are associated with lower worry. Academic institutions need to promote resilience to improve medical students' mental health.

\section{REFERENCES}

[1] Wu G, Feder A, Cohen H, Kim J, Calderon S, Charney $\mathrm{D}$ et al. Understanding resilience. Frontiers in Behavioral Neuroscience. 2013;7.

[2] Inam SB. Anxiety and Depression among Students of a Medical College in Saudi Arabia. Int J Health Sci (Qassim). 2007;1(2): 295-300.

[3] Richardson G. The metatheory of resilience and resiliency. Journal of Clinical Psychology. 2002;58(3):307-321.

[4] Building your resilience [Internet]. https://www.apa.org. 2012. Available from: https://www.apa.org/topics/resilience

[5] Southwick S, Charney D. The Science of Resilience: Implications for the Prevention and Treatment of Depression. Science. 2012;338(6103):79-82.

[6] Poudel-Tandukar K, Chandler G, Jacelon C, Gautam B, Bertone-
Johnson E, Hollon S. Resilience and anxiety or depression among resettled Bhutanese adults in the United States. International Journal of Social Psychiatry. 2019;65(6):496-506.

[7] Ristevska-Dimitrovska G, Stefanovski P, Smichkoska S, Raleva M, Dejanova B. Depression and Resilience in Breast Cancer Patients. Open Access Macedonian Journal of Medical Sciences. 2015;3(4):661665.

[8] Luthar S, Cicchetti D, Becker B. The Construct of Resilience: A Critical Evaluation and Guidelines for Future Work. Child Development. 2000;71(3):543-562.

[9] Robbins A, Kaye E, Catling J. Predictors of Student Resilience in Higher Education. Psychology Teaching Review. 2018;24(1):44-52. [10]APA Dictionary of Psychology [Internet]. Dictionary.apa.org. 2021. Available from: https://dictionary.apa.org/worry

[11]Dyrbye L, Power D, Massie F, Eacker A, Harper W, Thomas M et al. Factors associated with resilience to and recovery from burnout: a prospective, multi-institutional study 
of US medical students. Medical Education. 2010;44(10):1016-1026.

[12] Dyrbye L, Thomas M, Power D, Durning S, Moutier C, Massie F et al. Burnout and Serious Thoughts of Dropping Out of Medical School: A Multi-Institutional Study. Academic Medicine. 2010;85(1):94-102.

[13] Davidson, J. (2008). ConnorDavidson Resilience Scale (CDRISC) Manual. [ebook]Available at: http://www.connordavidsonresiliencescale.com/CD$\underline{\text { RISC\%20Manual\%2008-19-18.pdf. }}$

[14] Davidson, J., Baldwin, D., Stein, D., Pedersen, R., Ahmed, S., Musgnung, J., Benattia, I. and Rothbaum, B., 2008. Effects of venlafaxine extended release on resilience in posttraumatic stress disorder: an item analysis of the Connor-Davidson Resilience Scale. International Clinical Psychopharmacology, 23(5), pp.299-303.

[15] Yu X, Zhang J. Factor analysis and psychometric evaluation of the Connor-Davidson Resilience Scale (CD-RISC) with Chinese people. Soc Behav Personal. 2007; 35(1): 19-30 [16]Meyer T, Miller M, Metzger R, Borkovec T. Development and validation of the penn state worry questionnaire. Behaviour Research and Therapy. 1990;28(6):487-495.

[17]Peng L, Zhang J, Li M, Li P, Zhang $\mathrm{Y}$, Zuo X et al. Negative life events and mental health of Chinese medical students: The effect of resilience, personality and social support. Psychiatry Research. 2012;196(1):138-141.

[18]Hartley, M. Examining the Relationships Between Resilience, Mental Health, and Academic Persistence in Undergraduate College Students. Journal of American College Health. 2011;59(7):596-604.

[19] Nrugham, L., Holen, A. and Sund, A. Associations Between Attempted Suicide, Violent Life Events, Depressive Symptoms, and Resilience in Adolescents and Young Adults. The Journal of Nervous and Mental Disease. 2010;198(2):131136.

[20]Brailovskaia J, Schönfeld P, Zhang X, Bieda A, Kochetkov Y, Margraf J. A Cross-Cultural Study in Germany, Russia, and China: Are Resilient and Social Supported Students Protected Against 
Depression, Anxiety, and Stress?. Psychological

Reports. 2017;121(2):265-281.

[21] Koenig TW, Parrish SK, Terregino CA, Williams JP, Dunleavy DM, Volsch JM. Core personal competencies important to entering students' success in medical school: what are they and how could they be assessed early in the admission process? Acad Med. 2013;88(5):603-13.

[22] Ebrahimi, Abbas \& Keykhosrovani, Moloud \& Dehghani, Mostafa \& Javdan, Moosa. Investigating the Relationship between Resiliency, Spiritual Intelligence and Mental Health of a group of undergraduate Students. Life Science Journal. 2012 9(1), pp.67-70.

[23] Houpy J, Lee W, Woodruff J, Pincavage A. Medical student resilience and stressful clinical events during clinical training. Medical Education Online. 2017;22(1):1320187.

[24] Rahimi B, Baetz M, Bowen R, Balbuena L. Resilience, stress, and coping among Canadian medical students. Canadian Medical Education Journal. 2014;5(1):5-12.
[25] Bassols A, Okabayashi L, Silva A, Carneiro B, Feijó F, Guimarães G et al. First- and last-year medical students: is there a difference in the prevalence and intensity of anxiety and depressive symptoms?. Revista Brasileira de Psiquiatria. 2014;36(3):233-240.

[26] Brenneisen Mayer F, Souza Santos I, Silveira P, Itaqui Lopes M, de Souza $\mathrm{A}$, Campos $\mathrm{E}$ et al. Factors associated to depression and anxiety in medical students: a multicenter study. BMC Medical Education. 2016;16(1).

[27] Tempski P, Santos I, Mayer F, Enns $\mathrm{S}$, Perotta B, Paro $\mathrm{H}$ et al. Relationship among Medical Student Resilience, Educational Environment and Quality of Life. PLOS ONE. 2015;10(6):e0131535.

[28] Tempski P, Bellodi PL, Paro HB, Enns SC, Martins MA, Schraiber LB. What do medical students think about their quality of life? A qualitative study. BMC Med Educ. 2012;12:106. 